\title{
Circulating tumor cells and breast cancer-specific mutations in primary breast cancer
}

\author{
MICHAL MEGO ${ }^{1,2}$, MARIAN KARABA ${ }^{2}$, TATIANA SEDLACKOVA ${ }^{3}$, JURAJ BENCA ${ }^{2,4}$, GABRIELA REPISKA $^{3}$ \\ LUCIA KRASNICANOVA $^{5}$, JAN MACUCH ${ }^{2}$, GABRIELA SIEBEROVA $^{2}$, SILVIA JURISOVA ${ }^{1,2}$, DANIEL PINDAK ${ }^{2,6}$, \\ KATARINA KALAVSKA $^{1,2}$, JOZEF MARDIAK ${ }^{1,2}$ and GABRIEL MINARIK ${ }^{7}$ \\ ${ }^{1}$ Second Department of Medical Oncology, Faculty of Medicine, Comenius University; ${ }^{2}$ National Cancer Institute, \\ 83310 Bratislava; ${ }^{3}$ Institute of Molecular Biomedicine, Faculty of Medicine, Comenius University, 81108 Bratislava; \\ ${ }^{4}$ Department of Medicine, St. Elizabeth University, 81102 Bratislava; ${ }^{5}$ Institute of Medical Biology, \\ Genetics and Clinical Genetics, Faculty of Medicine, Comenius University, 81108 Bratislava; \\ ${ }^{6}$ Slovak Medical University, 83303 Bratislava; ${ }^{7}$ Department of Molecular Biology, \\ Faculty of Natural Sciences, Comenius University, Mlynska dolina, 84215 Bratislava, Slovakia
}

Received February 20, 2019; Accepted January 29, 2020

DOI: $10.3892 / \mathrm{mco} .2020 .2026$

\begin{abstract}
Circulating tumor cells (CTCs) play a pivotal role in tumor dissemination and progression, and are considered to be a critical part of the metastatic cascade. The aim of the present research article was to examine breast cancer-specific mutations in primary breast cancer (PBC) using targeted resequencing. A total of 78 patients with $\mathrm{PBC}$ were enrolled into this translational study. Reverse transcription-quantitative PCR assay for the expression of epithelial markers (CK19) or epithelial-to-mesenchymal transition (EMT)-related genes (TWIST1, SNAIL1, SLUG and ZEB1) was applied for identification of CTCs prior to surgery. Total DNA was isolated from fresh frozen primary tumors. Sequencing was performed by Agilent SureSelect target enrichment and Illumina paired-end sequencing on the MiSeq platform. The most commonly affected genes were TP53 (mutated in 21 tumors; $26.9 \%$ ), followed by PIK3CA (mutated in 16 tumors; $20.5 \%$ ) and $B R C A 1 / 2$ (mutated in 7 tumors, BRCA1 $\mathrm{n}=2$ and $B R C A 2$ $\mathrm{n}=5 ; 9.0 \%$ ). In our cohort, a significantly higher proportion of patients with epithelial CTCs harbored mutations in the
\end{abstract}

Correspondence to: Professor Michal Mego, Second Department of Medical Oncology, Faculty of Medicine, Comenius University, Klenova 1, 83310 Bratislava, Slovakia

E-mail: misomego@gmail.com

Abbreviations: CTCs, circulating tumor cells; EMT, epithelial-to-mesenchymal transition; EP_CTCs, epithelial CTCs; ER, estrogen receptor; HR, hazard ratio; HD, healthy donor; LVI, lymphovascular invasion; PBMCs, peripheral blood mononuclear cells; PBC, primary breast cancer; PR, progesterone receptor; RT-PCR, reverse transcription-polymerase chain reaction

Key words: circulating tumor cells, primary breast cancer, targeted resequencing, epithelial-to-mesenchymal transition, BRCA1/2
$B R C A 1 / 2$ genes in the tumor tissue. There were no mutations in specific genes associated with CTCs with the EMT phenotype. To the best of our knowledge, this study is the first to report a correlation between the presence of epithelial CTCs in the peripheral blood and mutations of the BRCA1/2 genes in primary tumor tissue.

\section{Introduction}

Breast cancer is the most commonly diagnosed malignancy among women, with 2,088,849 new cases of invasive breast cancer and 626,679 deaths reported in 2018 (1). Metastatic disease is typically an incurable condition associated with significant morbidity and mortality in breast cancer patients (2). The metastatic cascade is characterized as a multi-step process that includes escape of cancer cells from the primary tumor to a distant location, where they can potentially form new tumor colonies (3). To successfully complete the metastatic cascade, epithelial tumor cells detached from the primary tumor must penetrate into the peripheral circulation and ultimately undergo extravasation at the distant site and establish a new tumor focus. Previous findings have demonstrated that cancer cells undergoing epithelial-to-mesenchymal transition (EMT) acquire the characteristics necessary to go through the multiple steps of metastasis (4).

Circulating tumor cells (CTCs) essentially contribute to tumor dissemination and progression and are a crucial factor in the metastatic cascade $(3,5)$. The prognostic and predictive value of CTCs was consistently established by numerous trials, not only in metastatic, but also in primary breast cancer (PBC) (6-11). CTCs are closely associated with several biological processes, involving EMT, 'self-seeding', which is characterized as re-infiltration of the primary tumor by CTCs, as well as establishment of metastasis by more aggressive CTCs. Therefore, CTCs have been suggested to represent an indicator of treatment failure and disease progression $(12,13)$. Available experimental and translational research data 
indicate that the generation of CTCs is a continuous process spanning from one end of the spectrum (epithelial phenotype) to the other end (mesenchymal phenotype), and involves those with a partial EMT phenotype $(14,15)$. Accordingly, CTCs may be considered a heterogeneous population of cells, including CTCs with partial or complete EMT phenotype, and these subpopulations have different clinical and biological properties (5). In addition, CTCs display dynamic changes in epithelial and mesenchymal composition (15).

The most common somatic mutations in breast cancer are TP53, PIK3CA and GATA3, which are present in $>10 \%$ of all breast cancers (16). In a study including 216 patients, 12 genes (TP53, PIK3CA, GATA3, ESR1, MAP3K1, CDH1, $A K T 1, M A P 2 K 4, R B 1, P T E N, C B F B$ and $C D K N 2 A)$ were established as significantly mutated in metastatic breast cancer (mBC), while 8 genes (ESR1, FSIP2, FRAS1, OSBPL3, EDC4, $P A L B 2, I G F N 1$ and $A G R N$ ) were more frequently mutated in $\mathrm{mBC}$ as compared to early breast cancer (17). Several published studies have investigated the mutational status of CTCs (18-21); however, data on the association between gene mutations in primary tumor tissue and the presence of CTCs in the peripheral blood are lacking.

The aim of the present study was to identify the breast cancer-specific mutation status in PBC in association with the presence of various subpopulations of CTCs using targeted resequencing.

\section{Patients and methods}

Study patients. This translational study (Protocol TRU-SK 002; Chair: M. Mego) included 78 PBC patients with stages I-III after definitive surgery. Patients enrolled in this study were selected from a cohort of 427 PBC patients analyzed in a previous study detecting CTCs with EMT phenotype in $77(18.0 \%)$ patients with early breast cancer (22). Fresh frozen tumor tissue and status of CTCs in peripheral blood were available for all enrolled participants. To exclude the presence of distant metastasis, each patient underwent a full diagnostic evaluation. Patients with concurrent malignancies other than non-melanoma skin cancer in the previous 5 years were excluded. Patients' data regarding age, tumor stage, histological type, regional lymph node involvement, hormone receptor status, and human epidermal growth factor receptor 2 (HER2) status were also tabulated and statistically analyzed.

The study was performed between March 2012 and February 2015. Healthy donors $(n=60)$ were age-matched women without breast cancer who were recruited according to the Institutional Review Board (IRB)-approved protocol. The present study was approved by the Institutional Review Board (IRB) of the National Cancer Institute of Slovakia (Bratislava, Slovak Republic). Written informed consent was obtained from each participant prior to study enrollment.

Detection of CTCs in the peripheral blood. The peripheral blood samples used for CTC detection were collected into Vacutainer ${ }^{\circledR}$ Blood Collection Tubes EDTA (BD Biosciences) in the morning on the day of surgery. Reverse transcription-quantitative polymerase chain reaction (RT-qPCR) assay using $\mathrm{CD} 45^{+}$cell depletion for CTC enrichment was employed for CTC identification in the peripheral blood, as described previously $(23,24)$.
RNA extraction and cell lines. A RossetteSep ${ }^{\mathrm{TM}}$ kit (Stemcell Technologies, Inc.) was used for CD45 depletion in peripheral blood samples, according to the manufacturer's instructions. CD45-depleted cells were mixed with $500 \mu 1$ TRIzol LS reagent (Invitrogen; Thermo Fisher Scientific, Inc.) and stored at $-80^{\circ} \mathrm{C}$ until RNA was extracted according to the manufacturer's instructions. The precipitated pellet containing RNA was dissolved in $50 \mu \mathrm{l}$ nuclease-free water. Absorbance readings at $260 \mathrm{~nm}$ (median, $5.95 \mathrm{ng} / \mu \mathrm{l}$; range, 1.7-38.3 ng/ $\mu \mathrm{l}$ ) were used to determine RNA concentration. RNA extracted from HeLa, HCT116, MCF-7 and MDA-MB-231 cells served as the positive control.

Identification of gene transcripts in CD45-depleted subsets. EMT-inducing TF gene transcripts (TWIST, SNAIL1, SLUG and ZEB1) and epithelial antigen (CK19) were identified by RT-qPCR. In brief, the reaction was carried out in $25 \mu \mathrm{l}$ reaction volume containing $12.5 \mu \mathrm{l}$ QuantiFast Probe RT-PCR kit Master Mix, 0.25 $\mu$ l QuantiFast RT mix, 8.5 $\mu \mathrm{l}$ water and $1.25 \mu \mathrm{l}$ primers (Qiagen $\mathrm{GmbH}$ ). Isolated RNA was subsequently added (in a volume of $2.5 \mu \mathrm{l}$ ) to the reaction mix. The following TaqMan assays were obtained from Thermo Fisher Scientific, Inc.: TWIST1: Hs00361186_m1; SNAIL1: Hs00195591_m1; SLUG: Hs00161904_m1; ZEB1: Hs01566408_m1; GAPDH Hs99999905_m1; and CK19 Hs00761767_s1. Amplicons or probes spanned intron-exon boundaries, with the exception of CK19. Amplification was performed on a Roche LightCycler 480 II Real-Time PCR system (Roche Diagnostics $\mathrm{GmbH}$ ) using the following cycling program: $95^{\circ} \mathrm{C}$ for $10 \mathrm{~min}$, followed by 40 cycles at $95^{\circ} \mathrm{C}$ for $15 \mathrm{sec}$ and at $60^{\circ} \mathrm{C}$ for $60 \mathrm{sec}$. All the samples were analyzed in triplicate. Calibrator samples were run with every plate to ensure consistency of the PCR. For all fluorescence-based RT-PCR, fluorescence was detected between 0 and 40 cycles for the control and marker genes in single-plex reactions, which allowed for the deduction of the cycle quantification (Cq) value for each product. Establishment of GAPDH housekeeping gene expression was used as the expression control in the identification of the genes of interest. Target cDNA was measured by the $\Delta \mathrm{Cq}$ method with the formula: $1=2 \mathrm{Cq}$ (target-GAPDH) (25).

CTC definition. Patient samples with elevated CK19 gene transcripts compared with healthy donors were categorized as epithelial CTC-positive (CTC_EP), while patient samples with increased EMT-TF (TWIST1, SNAIL1, SLUG and ZEB1) gene transcripts compared with those of healthy donors were categorized as CTC_EMT-positive. To categorize a patient sample as CTC-positive, expression of at least one of the markers (either epithelial or mesenchymal) at levels above the defined cut-off was required. The highest expression levels of the $C K 19$ and EMT-inducing TF gene transcripts relative to that of $G A P D H$ were $3.4 \times 10^{-3}$ (median, $2.8 \times 10^{-6}$; range, $0-3.4 \times 10^{-3}$ ) for $C K 19$, $7.5 \times 10^{-4}$ (median, 0; range, $0-7.5 \times 10^{-4}$ ) for TWIST1, $3.8 \times 10^{-2}$ (median, 0.003135; range, 5.0 $\times 10^{-4}-3.8 \times 10^{-2}$ ) for SNAIL1 and $1.7 \times 10^{-1}$ (median, $1.4 \times 10^{-2}$; range, $2.2 \times 10^{-3}-1.7 \times 10^{-1}$ ) for $Z E B 1$, while $S L U G$ transcripts were not detected in any of the samples from healthy donors. The cut-off value determining CTC positivity was established according to the highest expression values in healthy donors (14). 
Table I. Patient characteristics.

\begin{tabular}{|c|c|c|}
\hline Variable & $\mathrm{N}$ & $\%$ \\
\hline All & 78 & 100.0 \\
\hline \multicolumn{3}{|l|}{ T-stage } \\
\hline 1 & 52 & 66.7 \\
\hline$>1$ & 26 & 33.3 \\
\hline \multicolumn{3}{|l|}{ N-stage } \\
\hline 0 & 48 & 61.5 \\
\hline$>1$ & 30 & 38.5 \\
\hline \multicolumn{3}{|l|}{ Grade } \\
\hline 1 and 2 & 50 & 64.1 \\
\hline 3 & 28 & 35.9 \\
\hline \multicolumn{3}{|l|}{ TNM classification } \\
\hline Stage I & 34 & 43.6 \\
\hline Stage II & 24 & 30.8 \\
\hline Stage III & 14 & 17.9 \\
\hline \multicolumn{3}{|l|}{ Histology } \\
\hline Invasive ductal carcinoma & 70 & 89.7 \\
\hline Other & 8 & 10.3 \\
\hline \multicolumn{3}{|l|}{ Hormone receptor status } \\
\hline Negative for both & 12 & 15.4 \\
\hline Positive for either & 66 & 84.6 \\
\hline \multicolumn{3}{|l|}{ HER2 status } \\
\hline Positive & 16 & 20.5 \\
\hline Negative & 62 & 79.5 \\
\hline \multicolumn{3}{|l|}{ Ki 67 (cut-off 20\%) } \\
\hline Low & 48 & 61.5 \\
\hline High & 30 & 38.5 \\
\hline \multicolumn{3}{|l|}{ Epithelial CTC } \\
\hline Present & 20 & 25.6 \\
\hline Absent & 58 & 74.4 \\
\hline \multicolumn{3}{|l|}{ CTC_EMT } \\
\hline Present & 28 & 35.9 \\
\hline Absent & 50 & 64.1 \\
\hline \multicolumn{3}{|l|}{ Any CTC } \\
\hline Present & 48 & 61.5 \\
\hline Absent & 30 & 38.5 \\
\hline
\end{tabular}

DNA isolation from the tumor. Tumor tissues were homogenized in liquid nitrogen and DNA was isolated from disintegrated cells using a DNeasy blood and tissue kit (Qiagen $\mathrm{GmbH}$ ) according to the original protocol. The most representative central part of the primary tumor was used for extraction of tumor DNAs.

Targeted resequencing

Panel of analyzed genes. The gene panel contained well-known genes associated with clinically relevant characteristics in breast cancer patients: $A C V R 1 B, A K T 1, A R I D I A, A T M, B A R D 1$, BRCA1, BRCA2, BRIP1, CASP8, CBFB, CDH1, CDKN1B, CHEK2, CTCF, CUL4, EP300, EPCAM, ERBB2, ERBB3,
FANCC, FRFR2, FOXA1, GATA3, GNPTAB, HIST1H3B, KMT2A, KRAS, MAP2K4, MAP3K1, MED23, MLH1, MLL3, MSH2, MSH6, MYB, NBN, NCOR1, NF1, PALB2, PIK3CA, PIK3R1, PMS2, PTEN, RAB40A, RAD51C, RAD51D, RB1, RUNX1, SF3B1, SPEN, STAG2, STK11, TBL1XR1, TBX3, $T P 53$ and $X R C C 2$. The customized SureSelect XT (Agilent Technologies, Inc.) probe-based enrichment strategy was used.

Genomic library preparation. DNA libraries were prepared by SureSelect QXT Target Enrichment Kit (Agilent Technologies, Inc.) according to the protocol for Illumina Multiplex Sequencing. Final DNA libraries were diluted to $13-20 \mathrm{pmol} / 1$ pools with 10-11 samples analyzed in parallel per one MiSeq sequencing run using a MiSeq sequencing reagent kit v3 150 cycles (Illumina, Inc.), set to run in the $2 \times 100$ mode.

Genomic data analysis. Following standard BaseSpace-based sequencing data analysis, read mapping and variant calling sequencing data were annotated and filtered using Ingenuity Variant Analysis (Qiagen $\mathrm{GmbH}$ ), which was set up to search for pathogenic variants associated with breast cancer. The identified pathogenic and likely pathogenic variants were verified by visualization in IGV and subsequently confirmed by Sanger sequencing.

Statistical analysis. The patients' characteristics were tabulated and summarized as the median (range) for continuous variables and frequency (percentage) for categorical variables. Categorical data were tested by Fisher's exact test or Chi-squared test. All P-values were two-sided, and $\mathrm{P} \leq 0.05$ was considered to indicate statistically significant differences. Statistical analyses were performed using NCSS 2007 statistical software (NCSS LLC) (26).

\section{Results}

Patient characteristics. The analyzed cohort included 78 patients with $\mathrm{PBC}$. The median age of the enrolled patients was 57 years (range, 33-83 years). The clinicopathological characteristics of the patients are summarized in Table I. The majority of the patients had invasive ductal (89.7\%), hormone receptor-positive $(84.6 \%)$ tumors and T1 stage disease $(66.7 \%)$. HER2/neu amplification was observed in $20.5 \%$ of the tumors.

In the present analysis, CTCs in PBC were detected in 44 $(61.1 \%)$ patient tumor samples, while no CTCs were detected in $28(38.9 \%)$ of the analyzed tumors. In order to improve clarity of published results only CTCs with epithelial or EMT phenotype were taken into consideration. In subgroup of CTCs-positive patients, 38.6\% (17/44) samples were characterized as epithelial CTCs (EP_CTC)-positive, while CTCs EMT (CTC_EMT)-positive phenotype was actually identified in $61.4 \%$ (27/44) of samples Table II.

Identification of mutations in breast cancer-related genes in the primary tumor and its association with the presence of CTCs in the peripheral blood. Six of the 78 samples (7.7\%) were excluded due to poor quality of DNA for analysis. Mutations were detected in $68.1 \%$ (49/72) of tumor samples, $36.1 \%(26 / 72)$ were classified as likely pathogenic and $61.1 \%$ $(44 / 72)$ as pathogenic while in $27.8 \%$ (20/72) of tumors no 
568

MEGO et al: CTCs AND BREAST CANCER-SPECIFIC MUTATIONS

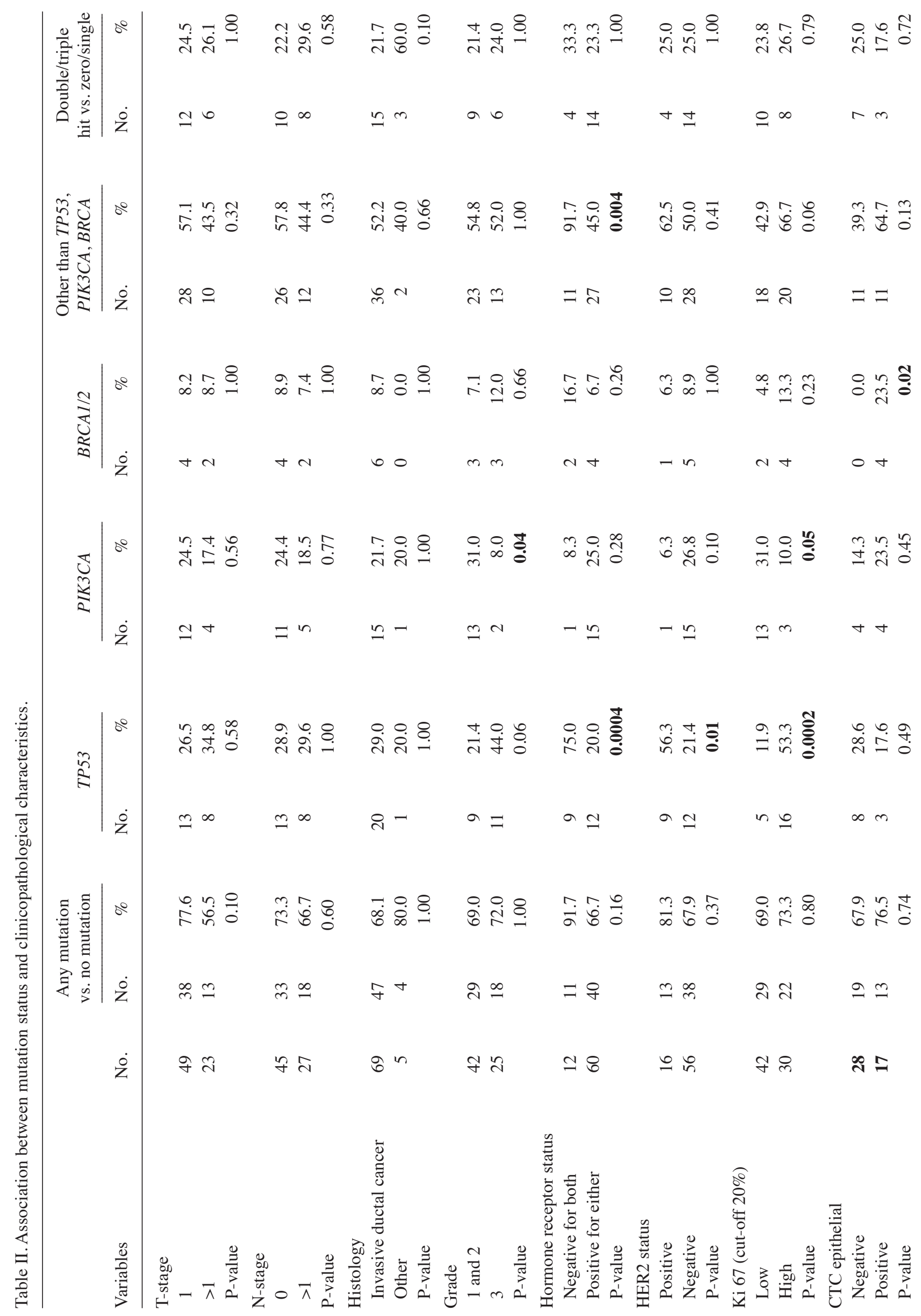


mutation was detected. In $43.1 \%$ (31/72) of tumor samples the patient's single pathogenic or likely pathogenic mutation was detected, in $18.1 \%$ (13/72) patient mutations in two genes were found, while in $4.2 \%(3 / 72)$ of tumor samples patient mutations in 3 genes were detected.

The most commonly affected genes were TP53, mutated in $25.0 \%$ (18/72) tumors, followed by PIK3CA mutated in $22.2 \%$ (16/72) tumors, BRCA1/2 in 9.7\% (7/72) tumors (2 for BRCA1 and 5 for BRCA2), CDH1 and GATA3 in 6.9\% (5/72) tumors. RUNXI and PTEN were mutated in $4.2 \%$ (3/72) tumors, $N F 1, B R I P 1$ and $A T M$ in $2.8 \%$ (2/72) tumors while $B A R D 1$, CDKN1B, GNPTAB, KRAS, PIK3R1 and PMS2 were mutated in $1.4 \%(1 / 72)$ tumor (Table III).

There were no differences in the number of tumors with pathogenic or likely pathogenic mutations between participants with detectable CTCs in the peripheral blood compared with patients with non-detectable CTCs (67.9 vs. 72.7\%, respectively; $\mathrm{P}=0.79$ ) (Table II). This difference remained unchanged when likely pathogenic mutations were excluded and no mutations vs. pathogenic mutations were compared (46.4 vs. 52.3\%, respectively; $\mathrm{P}=0.78$ ) (data not shown). Similarly, there were no differences in CTC status regarding mutations of TP53 and $P I K 3 C A$ and/or between tumors with single mutations vs. those with double/triple mutations. However, no BRCA1/2 mutations were detected in CTC-negative tumors compared with $9.7 \%$ of BRCA1/2 mutations $(\mathrm{P}=0.08)$ in CTCs-positive tumors. Moreover, 4 (23.5\%) patients with epithelial CTCs in peripheral blood had $B R C A 1 / 2$ mutations compared to $0(0 \%)$ patients without $B R C A 1 / 2$ mutations $(\mathrm{P}=0.02)$, while there was no significant correlation between mutation in the specific gene and presence of CTC_EMT-positive cells. Similarly, there was a trend for an increased mutation rate of genes other than TP53, PIK3CA and BRCA1/2 in CTC-positive compared with CTC-negative patients (61.4 vs. $39.3 \%$, respectively; $\mathrm{P}=0.09$ ) (Table II).

Examination of specific mutations revealed a significant association between TP53 mutation and HER2-positive status, hormone receptor negativity, high grade and increased tumor cell proliferation, as determined by the expression of Ki67. PIK3CA mutations were associated with lower grade and low proliferation rate, as determined by Ki67 (Table II).

\section{Discussion}

To the best of our knowledge, the present study was the first to reveal the association between the presence of epithelial CTCs in the peripheral blood and mutations of the BRCA1/2 genes in primary tumor tissue. We observed a numerically higher mutation rate in genes other than TP53 and PIK3CA and $B R C A 1 / 2$ in patients with CTC-positive compared with CTC-negative breast tumors; however, the differences did not reach statistical significance. The most commonly mutated genes in our patient cohort included TP53, PIK3CA, BRCA1/2, $C D H 1$ and GATA3, corresponding to the observed incidence in published datasets $(16,17)$. Similarly, Stephens et al detected somatic driver substitutions and small insertions/deletions (indels) in cancer genes previously implicated in breast cancer development, including AKT1, BRCA1, CDH1, GATA3, PIK3CA, PTEN, RB1 and TP53 (27). Cancer genes TP53, PIK3CA, ERBB2, MYC, FGFR1/ZNF703, GATA3 and CCND1 
Table III. Panel of specific mutations identified in PBC patients $(n=79)$.

\begin{tabular}{|c|c|c|c|}
\hline Patient no. & Category & Gene & Mutation effect \\
\hline 1 & No mutation & No mutation & No mutation \\
\hline 3 & Pathogenic & $C D H 1$ & Stop gain \\
\hline 4 & No mutation & No mutation & No mutation \\
\hline \multirow[t]{2}{*}{5} & Likely Pathogenic & $B A R D 1$ & Frameshift \\
\hline & Likely Pathogenic & TP53 & Frameshift \\
\hline 6 & NA & NA & NA \\
\hline 7 & Likely Pathogenic & GATA3 & Frameshift \\
\hline 8 & Likely Pathogenic & $R U N X 1$ & Frameshift \\
\hline 9 & Likely Pathogenic & PIK3RI & Frameshift \\
\hline \multirow[t]{2}{*}{10} & Pathogenic & PIK3CA & Missense \\
\hline & Likely Pathogenic & TP53 & Frameshift \\
\hline 11 & Likely Pathogenic & TP53 & Frameshift \\
\hline \multirow[t]{2}{*}{12} & Likely Pathogenic & $C D H 1$ & Frameshift \\
\hline & Pathogenic & TP53 & Missense \\
\hline \multirow[t]{2}{*}{13} & Pathogenic & $N F 1$ & Stop gain \\
\hline & Pathogenic & TP53 & Missense \\
\hline 14 & Pathogenic & TP53 & Missense \\
\hline 15 & Pathogenic & $A T M$ & Frameshift \\
\hline 16 & No mutation & No mutation & No mutation \\
\hline 17 & Pathogenic & $P I K 3 C A$ & Missense \\
\hline 18 & No mutation & No mutation & No mutation \\
\hline \multirow[t]{2}{*}{19} & Likely Pathogenic & BRIP1 & Missense \\
\hline & Likely Pathogenic & TP53 & Frameshift \\
\hline \multirow[t]{3}{*}{20} & Pathogenic Likely & $P I K 3 C A$ & Missense \\
\hline & Pathogenic & GATA3 & Frameshift \\
\hline & Pathogenic & $A T M$ & Stop gain \\
\hline 21 & Pathogenic & TP53 & Missense \\
\hline 22 & No mutation & No mutation & No mutation \\
\hline 23 & No mutation & No mutation & No mutation \\
\hline 24 & No mutation & No mutation & No mutation \\
\hline 25 & NA & NA & NA \\
\hline 26 & Pathogenic & GATA3 & Frameshift \\
\hline 27 & Pathogenic & $P I K 3 C A$ & Missense \\
\hline 28 & Pathogenic & $P I K 3 C A$ & Missense \\
\hline 29 & No mutation & No mutation & No mutation \\
\hline 30 & No mutation & No mutation & No mutation \\
\hline 31 & Pathogenic & $P I K 3 C A$ & Missense \\
\hline \multirow[t]{2}{*}{33} & Pathogenic & PIK3CA & Missense \\
\hline & Pathogenic & TP53 & Missense \\
\hline 35 & Pathogenic & $C D H 1$ & Stop gain \\
\hline 36 & Likely Pathogenic & GATA3 & Frameshift \\
\hline 37 & Pathogenic & TP53 & Missense \\
\hline 38 & Pathogenic & TP53 & Missense \\
\hline \multirow[t]{3}{*}{40} & Pathogenic & $B R C A 1$ & Frameshift \\
\hline & Pathogenic & TP53 & Missense \\
\hline & Pathogenic & $R U N X 1$ & Frameshift \\
\hline 43 & Pathogenic & $P I K 3 C A$ & Missense \\
\hline 44 & No mutation & No mutation & No mutation \\
\hline 45 & Pathogenic & $P I K 3 C A$ & Missense \\
\hline 46 & Likely Pathogenic & TP53 & Frameshift \\
\hline \multirow[t]{2}{*}{47} & Pathogenic & $B R C A 2$ & Frameshift \\
\hline & Pathogenic & $B R C A 2$ & Stop gain \\
\hline
\end{tabular}


Table III. Continued.

\begin{tabular}{|c|c|c|c|}
\hline Patient no. & Category & Gene & Mutation effect \\
\hline 48 & Pathogenic & TP53 & Missense \\
\hline 49 & No mutation & No mutation & No mutation \\
\hline 50 & No mutation & No mutation & No mutation \\
\hline 51 & Pathogenic & TP53 & Missense \\
\hline 52 & No mutation & No mutation & No mutation \\
\hline 53 & Likely Pathogenic & GATA3 & Frameshift \\
\hline 54 & Likely Pathogenic & $B R C A 2$ & Missense \\
\hline \multirow[t]{2}{*}{55} & Likely Pathogenic & $N F 1$ & Frameshift \\
\hline & Likely Pathogenic & TP53 & Frameshift \\
\hline 56 & Likely Pathogenic & TP53 & Frameshift \\
\hline \multirow[t]{2}{*}{57} & Pathogenic & GNPTAB & Frameshift \\
\hline & Pathogenic & $B R C A 2$ & Frameshift \\
\hline 58 & NA & NA & NA \\
\hline 59 & No mutation & No mutation & No mutation \\
\hline 60 & Pathogenic & $P I K 3 C A$ & Missense \\
\hline \multirow[t]{2}{*}{61} & Pathogenic & $P I K 3 C A$ & Missense \\
\hline & Pathogenic & BRIP1 & Frameshift \\
\hline 62 & No mutation & No mutation & No mutation \\
\hline \multirow[t]{3}{*}{63} & Pathogenic & $P I K 3 C A$ & Missense \\
\hline & Pathogenic & TP53 & Stop gain \\
\hline & Likely Pathogenic & PMS2 & Frameshift \\
\hline 64 & No mutation & No mutation & No mutation \\
\hline 65 & No mutation & No mutation & No mutation \\
\hline \multirow[t]{2}{*}{66} & Pathogenic & $P I K 3 C A$ & Missense \\
\hline & Likely Pathogenic & $B R C A 2$ & Missense \\
\hline 67 & Likely Pathogenic & TP53 & Missense \\
\hline \multirow[t]{2}{*}{68} & Likely Pathogenic & $\mathrm{CDH1}$ & Frameshift \\
\hline & Likely Pathogenic & $R U N X 1$ & Frameshift \\
\hline 69 & Pathogenic & $K R A S$ & Missense \\
\hline 70 & No mutation & No mutation & No mutation \\
\hline 71 & Pathogenic & $P I K 3 C A$ & Missense \\
\hline 72 & No mutation & No mutation & No mutation \\
\hline 73 & No mutation & No mutation & No mutation \\
\hline \multirow[t]{2}{*}{74} & Likely Pathogenic & PTEN & Frameshift \\
\hline & Likely Pathogenic & $C D K N 1 B$ & Frameshift \\
\hline \multirow[t]{2}{*}{75} & Pathogenic & PTEN & Stop gain \\
\hline & Pathogenic & PTEN & Frameshift \\
\hline 76 & Pathogenic & $B R C A 1$ & Frameshift \\
\hline \multirow[t]{2}{*}{77} & Pathogenic & $P I K 3 C A$ & Missense \\
\hline & Likely Pathogenic & $C D H 1$ & Frameshift \\
\hline 78 & Pathogenic & $P I K 3 C A$ & Missense \\
\hline
\end{tabular}

PBC, primary breast cancer.

were mutated in more than $10 \%$ of the analyzed cohort (27). $C D K N 1 B$ (also known as p27 or KIP1) normally inhibits the activation of cyclin E/CDK2 and cyclin D/CDK4 complexes, thus preventing cell cycle progression at phase G1 (28). Our analysis revealed one frameshift mutation in CDKN1B. These data confirm previously published results reporting $C D K N 1 B$ gene as a cancer gene (27). Stephens et al also identified 73 different combinations of mutated cancer genes.
In our analyzed group we found 18 different combinations of mutated cancer genes. Based on these results, we determined that most breast cancers differed from all others (27). Significant correlations between TP53 mutational status and certain clinicopathological characteristics of the primary tumor were in concordance with literature data (29). BRCA1/2 are tumor suppressor genes that are involved in DNA repair pathways associated with hereditary breast and ovarian cancer 
syndrome (30). A study by Erturk et al demonstrated that in $B R C A$-mutated triple-negative breast cancer, increased invasion and metastasis of cancer cells was mediated through the $B R C A$ mutation-associated decreased expression of miR-200c (31). Therefore, our results may be partially explained by $B R C A 1 / 2$ mutation-mediated increased invasion of breast cancer cells. Germline mutations of $B R C A$ are not associated with a higher rate of lymphovascular invasion (LVI) compared with non-mutated tumors (32); however, previous studies showed a correlation between LVI and the presence of CTCs $(33,34)$.

Data regarding the association between mutations in the primary tumor and the presence of CTCs in the peripheral blood are limited. While there are some studies that investigate the correlations between mutations in specific genes in CTCs and corresponding tumor tissue, trials addressing the association between mutational status of the primary tumor and the presence of CTCs are currently lacking. For example, in a study by Bredemeier et al, no correlation was observed between $P I 3 K C A$ mutations in cancerous tissue and the presence of CTCs in peripheral blood (19). In another study, there was a high match rate between specific mutations in CTCs and corresponding tumor tissue, but no data regarding the association between a specific mutation and the number of CTCs were reported (18). The cell-cell adhesion molecule CDH1 (E-cadherin) as well as CTNNB1 (beta-catenin), are involved in the process of cancer cell detachment from the primary tumor. Their association with EMT was revealed through several studies (35-37). The mechanism of EMT is predominantly activated by epigenetic events; however, data explaining the role of genetic are still limited. The study of Busch et al suggested that somatic mutations in $\mathrm{CDH} 1$ and CTNNB1 genes do not represent a major contributor to cancer cell detachment, and therefore presumably play a limited role in the etiology of tumor metastasis as well as in EMT (38). The association between CTC_EMT status and RFS (relapse-free survival) was evaluated in another study (22). This study including 427 PBC patients revealed the prognostic value of CTCs with EMT phenotype in all analyzed subgroups of patients. Patients enrolled into the present study were selected from the abovementioned cohort of PBC patients. In addition, CTCs with epithelial phenotype had no prognostic role in the abovementioned cohort (data not shown). It may be suggested that CTCs reflect specific biological characteristics of the tumor, similar to previous studies that showed no association between CTCs and common clinicopathological characteristics $(6,9,23)$. Due to intratumoral heterogeneity, we cannot exclude an association between mutational status in specific parts of the tumor (such as the tumor edge) and/or involvement of genes other than the ones examined in CTC generation.

There were certain limitations to the present study, such as the limited sample size with decreased statistical power of analyses, as well as the fact that we only assessed 56 breast cancer-associated genes. It was not possible to assess the impact of total mutational burden on CTC positivity. In addition, the study population was a homogenous cohort of patients, treatment-naive, without metastatic disease, in order to avoid the effect of the metastatic site heterogeneity factor on analyzed variables. Furthermore, the evaluation of epithelial and mesenchymal phenotype changes via BRCA gene silencing in vitro was not performed in present study.
In conclusion, a correlation between the presence of epithelial CTCs in the peripheral blood and mutations of BRCA1/2 genes in primary tumor tissue was identified, while there was no mutation in specific genes associated with CTC_EMT. The number of mutated breast cancer-associated genes was not associated with the presence of CTCs or the mutation of genes other than $B R C A 1 / 2$, suggesting that different factors may be involved in the generation and migration of CTCs. These data support the concept that CTCs are of high biological and clinical value in breast cancer.

\section{Acknowledgements}

Not applicable.

\section{Funding}

The present is the result of the implementation of project no. APVV-16-0010 and APVV-14-0327 funded by the Slovak Research and Development Agency.

\section{Availability of data and materials}

All datasets generated and analyzed during the present study are included in this published article.

\section{Authors' contributions}

MM, JMar and GM participated in the conception and design of this study. MM performed statistical analysis. GM, TS and KK were involved in CTC detection. GR, LK and GM performed next-generation sequencing. MK, JB and DP were involved in patient accrual and performed breast surgery. GS and JMac performed pathological examination. SJ was involved in patient accrual. MM drafted the article and all authors reviewed it critically for important intellectual content. All the authors participated in the acquisition, analysis and interpretation of data. All the authors have read and approved the final version of the manuscript for publication.

\section{Ethics approval and consent to participate}

The present study was approved by the Institutional Review Board (IRB) of the National Cancer Institute of Slovakia (Bratislava, Slovak Republic). Written informed consent was obtained from each participant prior to study enrollment.

\section{Patient consent for publication}

Not applicable.

\section{Competing interests}

Authors declare they have no competing interests.

\section{References}

1. Bray F, Ferlay J, Soerjomataram I, Siegel RL, Torre LA and Jemal A: Global cancer statistics 2018: GLOBOCAN estimates of incidence and mortality worldwide for 36 cancers in 185 countries. CA Cancer J Clin 68: 394-424, 2018. 
2. Greenberg PA, Hortobagyi GN, Smith TL, Ziegler LD, Frye DK and Buzdar AU: Long-term follow-up of patients with complete remission following combination chemotherapy for metastatic breast cancer. J Clin Oncol 14: 2197-2205, 1996.

3. Fidler IJ: Metastasis: Quantitative analysis of distribution and fate of tumor emboli labeled with 125 I-5-iodo-2'-deoxyuridine. J Natl Cancer Inst 45: 773-782, 1970.

4. Yang J and Weinberg RA: Epithelial-mesenchymal transition: At the crossroads of development and tumor metastasis. Dev Cell 14: 818-829, 2008.

5. Mego M, Mani SA and Cristofanilli M: Molecular mechanisms of metastasis in breast cancer-clinical applications. Nat Rev Clin Oncol 7: 693-701, 2010

6. Cristofanilli M, Budd GT, Ellis MJ, Stopeck A, Matera J, Miller MC, Reuben JM, Doyle GV, Allard WJ, Terstappen LW and Hayes DF: Circulating tumor cells, disease progression, and survival in metastatic breast cancer. N Engl J Med 351: 781-791, 2004.

7. Giuliano M, Giordano A, Jackson S, Hess KR, De Giorgi U, Mego M,Handy BC,Ueno NT, Alvarez RH, De Laurentiis M, et al: Circulating tumor cells as prognostic and predictive markers in metastatic breast cancer patients receiving first-line systemic treatment. Breast Cancer Res 13: R67, 2011.

8. Ignatiadis M, Kallergi G, Ntoulia M, Perraki M, Apostolaki S, Kafousi M, Chlouverakis G, Stathopoulos E, Lianidou E, Georgoulias V and Mavroudis D: Prognostic value of the molecular detection of circulating tumor cells using a multimarker reverse transcription-PCR assay for cytokeratin 19 , mammaglobin A, and HER2 in early breast cancer. Clin Cancer Res 14: 2593-2600, 2008.

9. Lucci A, Hall CS, Lodhi AK, Bhattacharyya A, Anderson AE, Xiao L, Bedrosian I, Kuerer HM and Krishnamurthy S: Circulating tumour cells in non-metastatic breast cancer: A prospective study. Lancet Oncol 13: 688-695, 2012.

10. Lv Q, Gong L, Zhang T, Ye J, Chai L, Ni C and Mao Y: Prognostic value of circulating tumor cells in metastatic breast cancer: A systemic review and meta-analysis. Clin Transl Oncol 18 322-330, 2016

11. Zhang L, Riethdorf S, Wu G, Wang T, Yang K, Peng G, Liu J and Pantel K: Meta-analysis of the prognostic value of circulating tumor cells in breast cancer. Clin Cancer Res 18: 5701-5710, 2012.

12. Enderling H, Hlatky L and Hahnfeldt P: Migration rules: Tumours are conglomerates of self-metastases. Br J Cancer 100 1917-1925, 2009.

13. Kim MY, Oskarsson T, Acharyya S, Nguyen DX, Zhang XH, Norton L and Massague J: Tumor self-seeding by circulating cancer cells. Cell 139: 1315-1326, 2009.

14. Mego M, Mani SA, Lee BN, Li C, Evans KW, Cohen EN, Gao H, Jackson SA, Giordano A, Hortobagyi GN, et al: Expression of epithelial-mesenchymal transition-inducing transcription factors in primary breast cancer: The effect of neoadjuvant therapy. Int J Cancer 130: 808-816, 2012.

15. Yu M, Bardia A, Wittner BS, Stott SL, Smas ME, Ting DT, Isakoff SJ, Ciciliano JC, Wells MN, Shah AM, et al: Circulating breast tumor cells exhibit dynamic changes in epithelial and mesenchymal composition. Science 339: 580-584, 2013.

16. Cancer Genome Atlas, Network: Comprehensive molecular portraits of human breast tumours. Nature 490: 61-70, 2012.

17. Lefebvre C, Bachelot T, Filleron T, Pedrero M, Campone M, Soria JC, Massard C, Lévy C, Arnedos M, Lacroix-Triki M, et al: Mutational profile of metastatic breast cancers: A retrospective analysis. PLoS Med 13: e1002201, 2016.

18. Bingham C, Fernandez SV, Fittipaldi P, Dempsey PW, Ruth KJ, Cristofanilli M and Katherine Alpaugh R: Mutational studies on single circulating tumor cells isolated from the blood of inflammatory breast cancer patients. Breast Cancer Res Treat 163: 219-230, 2017.

19. Bredemeier M, Kasimir-Bauer S, Kolberg HC, Herold T, Synoracki S, Hauch S, Edimiris P, Bankfalvi A, Tewes M, Kimmig R and Aktas B: Comparison of the PI3KCA pathway in circulating tumor cells and corresponding tumor tissue of patients with metastatic breast cancer. Mol Med Rep 15: 2957-2968, 2017.

20. Magbanua MJM, Rugo HS, Wolf DM, Hauranieh L, Roy R, Pendyala P, Sosa EV, Scott JH, Lee JS, Pitcher B, et al: Expanded genomic profiling of circulating tumor cells in metastatic breast cancer patients to assess biomarker status and biology over time (CALGB 40502 and CALGB 40503, Alliance). Clin Cancer Res 24: 1486-1499, 2018.
21. Paoletti C, Cani AK, Larios JM, Hovelson DH, Aung K, Darga EP, Cannell EM, Baratta PJ, Liu CJ, Chu D, et al: Comprehensive mutation and copy number profiling in archived circulating breast cancer tumor cells documents heterogeneous resistance mechanisms. Cancer Res 78: 1110-1122, 2018.

22. Mego M, Karaba M, Minarik G, Benca J, Silvia J, Sedlackova T, Manasova D, Kalavska K, Pindak D, Cristofanilli M, et al: Circulating tumor cells with epithelial-to-mesenchymal transition phenotypes associated with inferior outcomes in primary breast cancer. Anticancer Res 39: 1829-1837, 2019.

23. Cierna Z, Mego M, Janega P, Karaba M, Minarik G, Benca J, Sedlackova T, Cingelova S, Gronesova P, Manasova D, et al: Matrix metalloproteinase 1 and circulating tumor cells in early breast cancer. BMC Cancer 14: 472, 2014

24. Mego M,Karaba M, Minarik G, Benca J, Sedlackova T, Tothova L, Vlkova B, Cierna Z, Janega P, Luha J, et al: Relationship between circulating tumor cells, blood coagulation, and urokinase-plasminogen-activator system in early breast cancer patients. Breast J 21: 155-160, 2015.

25. Pfaffl MW: A new mathematical model for relative quantification in real-time RT-PCR. Nucleic Acids Res 29: e45, 2001.

26. NCSS 2007 Update (Version 1). NCSS, LLC, Kaysville, Utah, 2007. https://www.ncss.com/download/ncss/updates/ncss2007-v1/. Accessed August 8, 2019.

27. Stephens PJ, Tarpey PS, Davies H, Van Loo P, Greenman C, Wedge DC, Nik-Zainal S, Martin S, Varela I, Bignell GR, et al: The landscape of cancer genes and mutational processes in breast cancer. Nature 486: 400-404, 2012.

28. Chu IM, Hengst L and Slingerland JM: The Cdk inhibitor p27 in human cancer: Prognostic potential and relevance to anticancer therapy. Nature Rev Cancer 8: 253-267, 2008.

29. Santarpia L, Bottai G, Kelly CM, Gyorffy B, Szekely B and Pusztai L: Deciphering and targeting oncogenic mutations and pathways in breast cancer. Oncologist 21: 1063-1078, 2016.

30. King MC, Marks JH and Mandell JB; New York Breast Cancer Study Group: Breast and ovarian cancer risks due to inherited mutations in BRCA1 and BRCA2. Science 302: 643-646, 2003.

31. Erturk E, Cecener G, Tezcan G, Egeli U, Tunca B, Gokgoz S, Tolunay $\mathrm{S}$ and Tasdelen I: BRCA mutations cause reduction in miR-200c expression in triple negative breast cancer. Gene 556: $163-169,2015$.

32. Heerma van Voss MR, van der Groep P, Bart J, van der Wall E and van Diest PJ: Lympho-vascular invasion in BRCA related breast cancer compared to sporadic controls. BMC Cancer 10: 145,2010

33. Bystricky B, Cierna Z, Sieberova G, Janega P, Karaba M, Minarik G, Benca J, Sedlackova T, Jurisova S, Gronesova P, et al: Relationship between circulating tumor cells and annexin A2 in early breast cancer patients. Anticancer Res 37: 2727-2734, 2017.

34. Dawood S, Broglio K, Valero V, Reuben J, Handy B, Islam R, Jackson S, Hortobagyi GN, Fritsche H and Cristofanilli M: Circulating tumor cells in metastatic breast cancer: From prognostic stratification to modification of the staging system? Cancer 113: 2422-2430, 2008.

35. Kim K, Lu Z and Hay ED: Direct evidence for a role of beta-catenin/LEF-1 signalling pathway in induction of EMT. Cell Biol Int 26: 463-476, 2002.

36. Nawshad A, Lagamba D, Polad A and Hay ED: Transforming growth factor-beta signaling during epithelial-mesenchymal transformation: Implications for embryogenesis and tumor metastasis. Cells Tissues Organs 179: 11-23, 2005.

37. Kalluri R and Weinberg RA: The basics of epithelial-mesenchymal transition. J Clin Invest 119: 1420-1428, 2009.

38. Busch EL, Hornick JL, Umeton R, Albayrak A, Lindeman NI, MacConaill LE, Garcia EP, Ducar M and Rebbeck TR: Somatic mutations in CDH1 and CTNNB1 in primary carcinomas at 13 anatomic sites. Oncotarget 8: 85680-85691, 2017. 